\title{
Gender Balance and National Development: A case of the Nigerian Society
}

\author{
Esther Archibong $^{1 *}$, Chimaobi Okorie ${ }^{2}$, Ballantyne Ikpeme ${ }^{3}$ \\ 1. Department of Social Work, University of Calabar, Calabar, Nigeria \\ 2. Department of Social Work, University of Calabar, Calabar, Nigeria. \\ 3. Department of Social Work, University of Calabar, Calabar, Nigeria
}

\begin{abstract}
This paper examines the importance of gender balance in relation to national development bringing to fore the implications of gender inequality and highlighting the benefits of gender mainstream in the overall good of the nation's development. The objective of the study was to critically analyze the specific gender- laden issues responsible for the slow pace of development in the Nigerian society. The methodology adopted for this paper was the use of secondary data gathered from the University Libraries, news prints and journals. The quest for the attainment of national economic development and sustainable growth cannot be actualized without the recognition of the vital contributions of both genders. All 'hands must be on deck', a prerequisite for harmonious and functional drive in the desired direction of growth and development (both economic and social). The study also highlights the various dimensions women's contribution could assume in the Nigeria's national growth and development and proffered suggestions to ensure women gender equality in all spheres of activities in the country.
\end{abstract}

Keywords: Development, equality, gender, inequality, mainstreaming, growth.

DOI: $10.7176 /$ RHSS/10-6-09

Publication date:March $31^{\text {st }} 2020$

\section{Introduction}

The challenge of gender equality in Nigeria is really tough. This is probably because the task of including gender equality into national development is a mere guesswork or much on paper work in this country. The concern for "women in development" or "women progress" and "women involvement" in national activities as par the men is not only a street slogan in Nigeria but a governmental struggle and popularized programme.

In any case, this paper begins by investigating the historical underpinnings of the word Gender and proposing that "gender" implies significantly more than just woman or sex. The paper defines "gender equity" as uniformity of chances for all where one group of individuals are not liked or segregated over others, in the circulation of nourishment, shelter, medical services, education and job opportunities. In spite of the fact that there is across the board understanding that improvement ought to be wide based, women regularly remain underestimated simultaneously (World Bank Report 2011). Despite the fact that the encounters of individual women fluctuate and vary broadly, all in all as a group, they have more terrible experiences than men on various fronts, extending from destitution to poor insurance under the law, and from access to social insurance and health care.

In contrast to the subjects of different parts of the National Development Strategy, gender cannot be effortlessly disengaged as a different theme or division, given its crucial significance to all aspects, extending from business policy to farming, and from environmental policy to poverty alleviation. Truth be told, the subject of gender regularly winds up underestimated when it is isolated in such a manner. When considering national development, therefore, it is important that the wide-ranging significance of gender issues be figured out. By including all Nigerians-so as to fully harness the human capital of the country-, then would we be able to plan to upgrade the social good and achieve effective nation building. As the 1995 Commonwealth Plan of Action on Gender and Development expresses a key strategic objective of government should be to "integrate gender in all government agendas, strategies and programme and create a culture within government which is gender-sensitive and where gender issues become the responsibility and duty of all..." (UNDP 2011)

\subsection{Definitional issues}

In spite of the conspicuousness of discussions about women in development within both national governments and donor agencies, the ideas utilized are often vague and emotive. Unlike when they are plainly defined, two key concepts may be misunderstood.

- Gender equality: 
In simple terms, 'gender equality' has to do with uniformity of chances for all where one group of individuals are not preferred or discriminated over others, in the distribution of food, shelter, healthcare, job training and professional opportunities. It is a case whereby every group or individual is subject to the similar laws, with no individual or group having extraordinary benefits. It implies equivalent rights under the law, for example, security, voting rights, access to education and human services, wellbeing, respect, property rights and benefits as all others in the general public. It implies that everybody regardless of human imitators and conditions of birth should birth ought to appreciate indistinguishable rights and benefits from all others in the public arena. Each citizen, regardless of age, sex, race, class, income, language, tribe, education, property, religion, conviction, opinions, health or disability deserve equal treatment under the law and should not be outlandishly denied of their privileges to improve their lives. It likewise implies that every member of society is similarly liable for the well-being of the general public and ought to be relied upon and permitted to contribute their quota to national advancement. Furthermore, it unquestionably implies all individuals paying little heed to what group they belong, must be involved in the decision making procedure of the country

\section{- $\quad$ Gender balance}

Gender balance implies women having the same opportunities in life as men including the ability to participate in the public sphere. Gender equity means the sameness in life outcomes for women and men, recognizing their different needs and interests, and requiring a redistribution of power and assets. It is about being aware of gender differences and balancing interventions, plans, teams etc. to reflect that - it does not mean having to artificially determine that every team, every group of beneficiaries has equal numbers of men and women. It is also about chances and boundaries e.g. 20 women could be in a meeting with 15 men but if the women are not given opportunity to speak, there is gender imbalance.

\section{- $\quad$ National Development}

Development implies various things to various individuals. Mabogunje (1980) distinguishes it to be monetary, development, modernization, distributive equity, financial change and spatial revamping. A few people anyway focus on material thriving as a definitive of improvement endeavors. For example, Razari (2003) describes development or advancement as a kind of social change in which new thoughts are introduced within a social framework to produce higher per capital incomes and levels of livelihoods through more production, methods and improved social organizations.

Gladwell (2016) accepted that development should mean "a widely participatory procedure of social changes in society expected to generate social and material progression (including greater equality, freedom and other esteemed characteristics) for most individuals through gaining control over their environment" Murrel, (2012) has opined that women are prominent among the poor in the world today and they are more in the rural areas. Their annual incomes throughout the world have declined so severely of late they had fallen beneath poverty line.

National development is the capacity of a country or nations to improve the social government assistance of the individuals e.g by giving social conveniences like quality education, consumable water, transportation foundation, clinical consideration, and so on. The term National Development in an expansive and improvement sense incorporates general development issues such as improvement of human capital, economy, social improvement, democracy building, national defense, and other areas.

\subsection{Gender as a Crosscutting Issue}

The accomplishment of gender parity, value and women's strengthening and empowerment are acknowledged development objectives and basic spring boards for Nigeria to become an advanced country by 2020. Gender is accepted here as a crosscutting issue which reinforce the fact that women and men have different problems and therefore different needs in areas such as administration or governance, the economy, wellbeing, education. In general, people are brought into the world male or female with certain related natural attributes and sexual contrasts. The natural body turns into a 'framework' on which society (people and organizations) develops social constructs, social implications identified with appropriate sex-connected behaviors referred to as masculine and feminine characteristics. The term 'gender' portrays these socially developed contrasts between the sexes and to the social, economical and socially and political relations between men and women (Moghadam 2000). Theses standards in turn characterize what is considered 'suitable' conducts for women and men, and decide differential access to social, monetary and political power, and the allotment, targeting, use and control of assets and resources by individuals. Gender relations vary as indicated by economics and social states of the general public and vary among social and ethnic groups. The challenge with gender is the differential and lower esteem allocated to feminine roles and obligations in many societies. 
Gender philosophies and standardizing social structures not just give the basis proliferation of sex-suitable roles and relationships and the development of masculinity and femininity yet additionally exemplify convictions and perspectives, which supports sex stratification and finally, also decide access to material assets and contrast in status, power and privilege among women and men (Oakley 2002). This unevenness between the genders in terms of both material and non-material assets of power and status has for some times been established and recognized.

The government of Nigeria has reacted to these issues by the establishment of a Bureau or Ministries of women's Affairs, through specially appointed tasks and programs, and in addition to other things planned for accomplishing gender equality and improving the status of women. The objective of gender balance is to guarantee equivalent chance and equity outcome taking into account the possibility that both women and men may freely make different life decisions (Adebayo 2007). These decisions are frequently compelled by foundational and auxiliary obstructions, for example, legal frameworks and institutional structures. Again, gender equity refers to removal of differences which attributes lower value to women's contribution and prolong the existence of unequal power and resources; and includes reasonableness and equality of chance where gender is not a basis for discrimination and imbalance. In a gender equitable society both women and men receive and experience equal status, rights, levels of obligations, and access to power and resources. This empowers them to make their own informed, feasible and free life decisions. The anticipated outcome of implementing as rights-based method is a people-centered focus and the creation of a society that is set apart by shared respect and worthiness for all. (Mayoux 2005)

\subsection{The Issue of Gender balance in National Development}

Women are at the core of development as they control most the non monetary economy (subsistence, agriculture, bearing children, domestic work and so on) and assume a significant role in the monetary economy (trading, wage labour, business (Obi 2001). In all societies in the world, women work both around the home and outside the home. The most current interest in International developmental programme is women. The woman as a person is a specialist of generation of itself. This places her in the position of the life blood of the entire human kind. She is the primary instructor and teacher, one who keeps and maintains the home, the one who maintains peace, the icon of magnificence and major builder of the character of the child. She is a mother of the humanity. As mothers and wives, women do apply significant effects on the productiveness of male workers. As workers in their own rights, they can conveniently be linked to the rejected stone in the Bible which has become the cornerstone of the house. By their sheer- mental, physiological and cognitive make up, they do perform more than simple complimentary roles in the production process (Okeowo 2012).

A large portion of these commitments and contributions by women had not been perceived until recently when the United Nations declared the Decade for Women (1976-1985) making it compulsory on governments to concentrate on issue of women as an indispensable segment of national development. In 1979, the United Nations General Assembly embraced the Convention on the Elimination of all forms of Discrimination Against Women. Resulting conferences on women were held in Copenhagen, Denmark 1980, Nairobi in Kenya 1985 and Beijing in China 1995. However, an International news magazine "Africa Today" reported in July 1995 that the full execution of the considerable number of procedures and suggestions of the different meetings and conferences on women issues had still not been accomplished and the eagerness was becoming weaker or disappearing. As indicated by the magazine, the UN itself reported that 6 out of the 184 ambassadors to $\mathrm{UN}$ are women and just four out of the 32 UN specialized agencies and programmes are headed by women.

Returning home in Nigeria, the 1985 constitutional conference in Nigeria had just 8 women out of a total of 369 delegates. Much of women's work stay undetectable, unremunerated and unrecognized. But women are now challenging the existing state of affairs with the introduction of means and processes to right the so called "cultures wrong". Women's voices are currently being heard seeking for an improvement in their financial and economic status and for the acknowledgment of their huge contributions to national development (Kalu \&Aminu-Philips, 2018).

Lately in Lagos, the Minister of Commerce and Industry, said at a one-day Women in Export Development Summit organized by the Nigerian Export Promotion Council, with the theme "Empowering Women to Power Trade". That so little had been done to explore women's capability to contribute to national development. He said this emphasizing the need to reduce the existing gender disparity in Nigeria, He noticed that the country would realize its maximum capacity when gender issues at play in financial, economic, social, political circles were tended to. As indicated by him, numerous national and international approaches and activities had been embarked on to address gender-related issues in the society. The Minister recommended, that for Nigeria to be strong the initial 20 leading economies by the year 2020, the production activity and capabilities of both men and women must be acknowledged. (http://www.punch.com/Articl.aspx) 
The analytical investigation of gender balance recognizes that various social standards and values pertaining to women and men bring about advancement and development policies and practices having a differential influence on women and men; and it contends along these lines, the improvement of approaches and practices that assess and address areas of weakness that emerge from the structure of gender relations. There is a more prominent consciousness to address the mythical hindrances of women as active participants in the development process, and to concentrate on advancing a more active and dynamic role for men in the home. The objective of this approach is to give more confidence to disadvantaged women and men changing inconsistent gender relations and so promote more sustainable development for both women and men.

\subsection{What is the way forward?}

\section{- Transformation by Mainstreaming.}

Having this awareness of the systemic and disadvantageous nature of gender inequality, gender mainstreaming, becomes endorsed by major global development activists as the strategy for achieving needed change of gender relations in all spheres of society endeavours. Gender mainstreaming means a set of procedures involved in assessing the implications for women and men of any existing or designed societal action. It is also a mechanism for making both men and women concerns and experiences an important part of the design, put into practice monitor and evaluate policies and programmes in all societal spheres. This strategy is targeted at producing a more balanced and appropriate condition to development where the needs of both urban and rural populations, as well as vulnerable groups are met.

According to Okeowo (2012), Gender mainstreaming is a world-wide accepted approach for promoting uniformity of opportunities and gender equality. Mainstreaming is not an end in itself but an approach, a means to achieve the objective of gender equality. Mainstreaming involves making certain that gender perspectives and attention to the goal of gender equality remain the focus of all activities or policies of development, be it in the aspect of research, advocacy/dialogue, legislation, resource distribution, planning, implementation and monitoring of programs and projects.

Bailey (2017) perceives it as the incorporation of the gender views and outlook into every stage of policy processes in terms of designing, implementation, supervising and examining for effectiveness. This is aimed at promoting equality between women and men. In addition, it means assessing how policies impact on the life and position of both women and men taking responsibility to re-address them if necessary. This is the way to make gender equality an absolute and tangible actualization in the lives of women and men creating space for everyone within organizations and communities (Norris, 2000). Mainstreaming a gender perspective is the process of ensuring that women and men benefit equally, and inequality is not sustained. The ultimate goal of mainstreaming is to achieve gender equality.

Mainstreaming is not tied "woman's component"' or even a 'gender equality component'". It goes past expanding women's participation; it implies bringing the experience, knowledge, and interests of women and men to be relevant on the development plan. It may involve recognizing the need for changes in that plan. It might require changes in objectives, methodologies, and activities so that both women and men can impact, take part in, and benefit from development activities. The goal of mainstreaming gender equality is hence the transformation of unequal social and institutional structures into equal and just structures for both men and women.

\section{- $\quad$ Fundamental Standards of Mainstreaming}

Duty towards the implementation of mainstreaming technique is system-wide, and rests at the highest levels within agencies, according to Carolyn Hannan, Director of the UN Division for the Advancement of Women. Other standard or principles include:

- $\quad$ Adequate responsibility mechanisms for checking progress need to be set up.

- The establishment of identity of issues and problems across all areas of activity should portray the diagnosis of gender disparities.

- $\quad$ No assumptions about neutrality of issues from a gender- equality perspective should be made.

- $\quad$ Gender examinations and checks should be consistently carried out.

- Clear political will and designation of adequate resources for mainstreaming including additional monetary and human resources if necessary, are important for translation of the concept into practice.

- Gender mainstreaming need that efforts be made to widen women's impartial cooperation at all levels of decision-making.

Mainstreaming is not a substitute to the need for targeted, women-specific strategies and projects, and positive legal backing, nor does it do away with the need for gender units or central focuses. 
Education of women offers them the opportunity to take an interest and add to national development. This is on the grounds that women's education increases economic growth and financial development (Abu and Klassen, 2004). Benwari \&Igwesi (2009) likewise enumerated some areas where female education can be beneficial to national development as:

1. Increased involvement in the work force and earning power.

2. Creating intergenerational education benefits

$3 . \quad$ Lowering women's fertility rate.

4. Lowering maternal mortality infection

5. Protecting against HIV/AIDS infection

6. Reducing infant and child death rates

Most educated women acquire more earnings than the uneducated ones. This increases the degree of their commitments to the upkeep and development of themselves, their family members and the general public. Over population is a social problem that hinders smooth development. The education of women adds to national development on the grounds that educated women bring forth fewer healthier children than the uneducated ones. This is because their marriage is likely to be delayed as a result of formal education.

Reduction of maternal death rates, protection against HIV/AIDS infection and lowering of infant and newborn mortality rates are completely connected to women education because educated women not only know the significance of pre and post natal care, seek medical care for their children and receive information about HIV/AIDS infection, they also utilize this knowledge because they understand how to interpret and put it into practice. This guarantees that they and their family members enjoy wellbeing.

Resulting from the understanding of the role of educated women in national development, the Federal Government of Nigeria made deliberate effort to ensure that women are given opportunities to contribute their quota in decision making in the country. This was done by delegating jobs to women and fixing them into important positions in the society.

Many educated women have therefore contributed immensely to the development of their society. Some have become legislators, Heads of different organizations, professionals and experts in diverse firms. In Nigeria, there are many of such women as Professor Alele Williams a former Vice Chancellor of University of Benin and former Minister of Foreign affairs Dr (Mrs) Ngozi Okonjo Iweala, who contributed immensely to the economic development of Nigeria. A former Director of NAFDAC and member of information and communication Professor (Mrs.) Dora Akunyili also marks in the history of development in Nigeria especially in the fight against fake drugs and the rebranding of Nigeria's image. This is just to mention a few of Nigerian women who have contributed immensely to the development of Nigeria. Other women who had served Nigeria in different capacities as ministers include the Minister of Petroleum resources, Mrs. Deziani Alison-Madueke and the Minister of Education, Professor, Mrs) Ruquayyatu Rufia, some of the women were in the House of Representatives while some in the National Assembly contributing useful ideas that ensured the smooth running of national affairs.

In the African countries too, educated women are making impact in the national development of their countries. For instance, Dr. (Mrs) Erlen Johnson Sirleaf of Liberia has become the first African Women President. As an economist, she is out to raise from the dust the economy of Liberia. Mrs. Alice Zomukunda also served as the Vice President of Burundi. The Prospects for women education in Nigeria today are very high. Although, observation shows that there are still differences in the Western type education of women along religious, social, ethnic and geographical lines, it could be argued that's education of the females and their participation in nation building has improved tremendously. There is no fain saying that the implementation of gender balance, if effectively carried out, will lead to the social, political, mental and moral emancipation of the society and the general development of the nation.

\section{Conclusion}

Today, numerous nations of the world are putting forth attempts to close the gap between men and women in politics. But in Nigerian the representation of women in Government despite the fact it has improved than before is still very low compared to what obtains in other nations of the world, particularly in the developed nations. The representation of women in the last political decision was poor just few women made it to 109 members' senate house and lower house of representatives. So to speak, the number of serving female Ministers is still very few. There is no doubt that women have potentials and rights to contribute genuinely to the development of their country. Therefore, the Nigerian government must works in the direction of achieving gender equality in 
democratic governance, increase women participation and access to politics. It must be understood that the role of women as home makers cannot be down played in that it equally has an extended effect on their duties responsibility.

\section{Conflict of Interest:}

On behalf of all authors, the corresponding author states that there is no conflict of interest.

\section{References}

Adebayo, A. (2007) Righting Patriarchal Wrongs: A Study of African women in Recent Francophone African Literature. Paper Presented at the $50^{\text {th }}$ Conference of the African Studies Association, New York 18-12 October.

Alvesson, M. and Billing, Y. (1997) Understanding gender and organizations: London: Sage.

Bacchi, Carol Lee. (1999) Women, Policy and Politics: the construction of policy problems. London; Sage

Bailey, B (2017) and 'Gender and National Development Planning' JA Cambridge: Cambridge University Press.

Benwari, N. N \& Igwesi, B.N (2009) Gender Equity in Education: A panacea for Sustainable Development. Journal of international gender studies, (5), 103-112

Gherardi, S. (1995) Gender symbolism and organizational culture. London: Sage.

Gladwell, M, (2016). The tipping point: how little things can make a big difference. London. Little Brown and Company

Kalu, N.E \& Amini-Philips, C. (2018), Gender Equity and Economic Empowerment: Prospects \& Challenges. Journal of International Gender Studies, (5) 164-165

Mayoux, L. (2005), 'Gender and Empowerment Concepts', Available at http://www.genfinance.net. Retrieved 17, May 2019

Molagun, H.M. Taiwo M.B \& Ajere, R.O (2000). A Guide to Sociology of Education. Llorin; Blessed James Publications.

Moghadam, V. (2000) 'Transnational feminist networks: collective action in an era of globalization.' International Sociology, 15:57-86

Morgan, N. (1988). The equality game: women in the federal public service (1908-1987) Ottawa: Canadian Advisory Council on the Status of Women.

Norris, P. 2000. A virtuous circle: political communication in post-industrial societies. Cambridge: Cambridge University Press.

Norris, P. (1997) Women, media and politics. New York: Oxford University Press .

Oakley, A. (2002). Gender on Planet Earth. Cambridge: Policy Press.obi, C.N (2001). Women Education and Nation Building. Nigerian Journal of Curriculum \& Instruction, 10(6):56-59

Okeowo, S. (2012) Female Education and productivity. Ilorin. Journal of Teacher Education (1) 2:157-160

Razavi, S (2003) Women's changing roles in the context of economic reform and globalization'. Background paper for EFA Global Monitoring Report 2003/04

World Bank Report (2011) Engendering Development-Through Gender Equality in Rights Resources and Voices. World Bank Policy Research Report. New York. Oxford University Press.

UNDP (2016) Human Development Report 2006 New York. 